
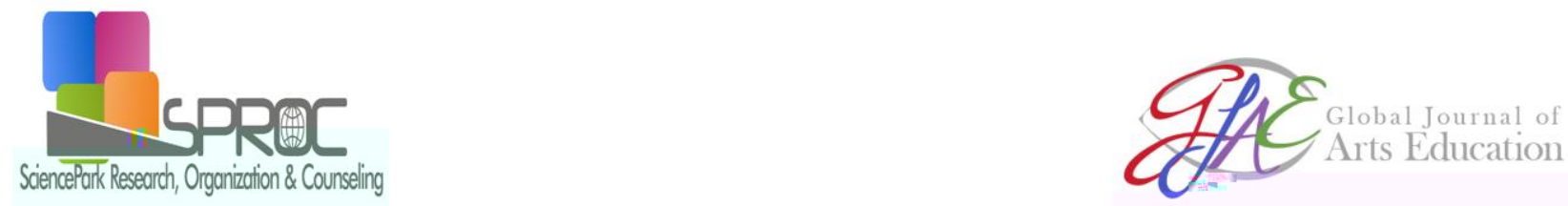

www.gjae.eu

\title{
Two aspects of art: Suicide mental illness and therapy
}

Hakkı Engin Giderer*

Suggested Citation:

6

Global Journal of Arts Education.

$\mathrm{R}$

$\mathrm{R}$

Abstract 
1. Introduction

2. Suicide and Madness

I

$\mathrm{R}$

R

3. Example of Van Gogh and Others 
$\mathrm{R}$

$\mathrm{R}$

I

$\mathrm{R}$

$\mathrm{R}$

$\mathrm{R}$

I

I 
4. Therapy

R

$\mathrm{R}$ 
5. Conclusion

$\mathrm{R}$ 


\section{References}

$\mathrm{R}$ Art Psychotherapy, 4 $\mathrm{J}$ ct

ct

Fakültesi Dergisi, 36

Üç Boyutluluk Korkusu, Sanat Psikoterapi ve Psikoz
Uludağ Üniversitesi Tıp
$\mathrm{J}$

I
$\mathrm{J}$

Bilim Teknik Dergisi, 497

Turkiye'de Sanat Dergisi, 62

I

$\mathrm{R}$

Dergisi

P Dunya Sanat Dergisi, 48

Akıl Hastalığı ve Sanatci. 